\title{
FEATURES OF CONNECTIVE TISSUE METABOLISM AND MICROELEMENTS IN BLOOD SERUM OF PREGNANT WOMEN WITH CERVICAL INSUFFICIENCY
}

\author{
Sadrudin Magomedov \\ Laboratory of Biochemical and Clinical Analysis \\ State Institution "The Institute of Traumatology and Orthopedics" of \\ National Academy of Medical Sciences of Ukraine \\ 27 Bulvarno-Kudriavska str., Kyiv, Ukraine, 01601 \\ alexandr@magomedov.kiev.ua \\ Iryna Zhabchenko \\ Department of Pathology of Pregnancy and Delivery \\ State Institution "Institute of Pediatrics, Obstetrics and Gynecology \\ named after academic A. M. Lukyanova of National Academy of Medical Sciences of Ukraine" \\ 8 Platona Maiborody str., Kyiv, Ukraine, 04050 \\ izhab@urk.net \\ Viktor Oleshko \\ Department No. 3 of Obstetrics and Gynecology \\ O. O. Bogomolets National Medical University, \\ 13 Taras Shevchenko blvd., Kyiv, Ukraine, 01601 \\ docolv@gmail.com

\section{Larysa Polishchuk} \\ Laboratory of Biochemical and Clinical Analysis \\ State Institution "The Institute of Traumatology and Orthopedics" of \\ National Academy of Medical Sciences of Ukraine \\ 27 Bulvarno-Kudriavska str., Kyiv, Ukraine, 01601 \\ lara25@i.ua \\ Nellia Korniets \\ Department of Obstetrics and Gynecology \\ State Institution "Lugansk State Medical University" \\ 22 Budivelnykiv str., Rubizhne, Ukraine, 93012 \\ kornietsnellia@gmail.com \\ Olga Krynicka \\ Laboratory of Biochemical and Clinical Analysis \\ State Institution "The Institute of Traumatology and Orthopedics" of \\ National Academy of Medical Sciences of Ukraine \\ 27 Bulvarno-Kudriavska str., Kyiv, Ukraine, 01601 \\ olenka19@ukr.net
}

\footnotetext{
Abstract

The preterm deliveries are the leading cause of the perinatal morbidity and represent important mortality indicators. Functional cervical insufficiency, which is a phenotypic manifestation of undifferentiated connective tissue dysplasia, plays the main role in the development of pregnancy complications in primigravidas (women pregnant for the first time) and primiparas (women giving birth for the first time).

Aim of the research: to study the indicators of connective tissue metabolism and basic microelements in order to determine the role of undifferentiated connective tissue dysplasia in the pathogenesis of functional cervical insufficiency during pregnancy.
} 
Methods. The 101 pregnant women (the main group) at the 22-32 week gestation period which were diagnosed with "Functional cervical insufficiency" were examined, as well as 34 pregnant women with the physiological obstructive function of the cervix (the control group). Utilizing immunoenzyme analysis we measured in blood serum the concentration of Total P1NP the amino-terminal propeptide of procollagen type I a marker of synthesis, and $\beta$-CrossLaps resorptions marker of the connective tissue. Utilizing the automatic analyzer of electrolytes and a set of reagents for their determination we estimated the content of microelements $\mathrm{Na}^{+}$, $\mathrm{K}^{+}, \mathrm{Mg}^{2+}, \mathrm{Ca}^{2+}$ and total $\mathrm{Ca}$ and $\mathrm{P}$.

Results. The functional cervical insufficiency in pregnant women was indicated by cervical shortening up to $22.88 \pm 1.02 \mathrm{~mm}$, and the majority of women (76.2 \%) had phenotypical manifestations of undifferentiated connective tissue dysplasia. We found a significant increase in the concentration of marker of synthesis Total P1NP, whereas the concentration of resorption marker $\beta$-CrossLaps remains normal, and strong reverse correlation $(\mathrm{r}=-0.7362)$ between the index of cervix length and concentration of marker of connective tissue synthesis Total P1NP. We detected a significant increase in the concentration of total and ionized calcium, total phosphorus, deficiency of ionized magnesium, potassium and sodium that lead to changes in the structure of connective tissue and reduction of cervical obstructive function.

Keywords: pregnancy, undifferentiated connective tissue dysplasia, markers of synthesis and resorption, microelements.

\section{Introduction}

Premature delivery is one of the most common complications of pregnancy. In the general population of pregnant women, the rate of premature delivery is $10-30 \%$ and does not decrease $[1,2]$. Cervical insufficiency $(\mathrm{CI})$ is one of the leading reasons of extremely early and early preterm deliveries. Clinically CI happens at 22-28 weeks of pregnancy leading to premature deliveries and such newborns have indicators of perinatal morbidity and mortality $[3,4]$.

The mechanism of the probable miscarriage in a case of functional CI is not studied completely. Contrary to the anatomical and congenital one, the functional CI is based on the relative or absolute progesterone deficiency. The lack of progesterone, which provides a physiological functional condition of the isthmus and the internal orifice of the uterus, causes to the development of premature delivery of primigravida $[5,6]$. The routine practice lack preclinical diagnostic criteria and recommendations for antenatal care of pregnant women with functional CI, which leads to late diagnosis, complications, and loss of pregnancy $[1,5]$. The causes of functional CI are numerous and various $[7,8]$. The least studied aspects of the problem are the role of undifferentiated connective tissue dysplasia (UCTD) and the violations of the nutritional status in the genesis of extremely early and early preterm deliveries.

Numerous studies of recent years show the importance of normal functions of connective tissue (CT) for the female organism in the nonpregnant state as well as in the pregnant one $[9,10]$. The CT's proper functional condition is important for the regulation of morphogenesis and the functional regulation of the reproductive system, namely ovulation, permeability of cervical mucus, transport function of the fallopian tubes, endometrium decidualization process, physiological implantation and remodeling of the uterus during pregnancy, the formation of the placental barrier and the functioning of the vascular endothelium. At the same time, modern studies show numerous pregnancy complications in patients with UCTD such as miscarriage and premature delivery, preeclampsia, placental dysfunction, premature rupture of amniotic membranes $[9,11]$. The process of delivery and the postpartum period are mostly complicated by abnormalities of labor activity, birth trauma, bleeding and disorders of wound repair after surgery $[3,4]$. It suggests that there is a disturbance in the ratio between connective and muscle tissues, which are characteristic for UCTD. Similar changes in the form of reduction of the collagen amount and increased mass of muscle tissue are observed in a case of cervical insufficiency $[3,11]$.

The nutritional status is crucially important for the development of pregnancy and normal functioning of CT $[12,13]$. Dysmicroelementosis, magnesium and calcium deficiency, in particular, cause changes in CT structure [14]. Magnesium deficiency affects the structure of collagen, elastin and collagen fibers due to the synthesis slowdown of structural components of CT and the 
activation of degradation processes $[15,16]$. Calcium ions determine the elastic properties of CT components and take part in the activation of elastase $[14,17]$.

Despite all known information the significance of CT insufficiency and the role of imbalance of the nutritional status system in the pathogenesis of functional CI has not been thoroughly studied.

\section{Aim of the research}

Therefore, we aimed to study the indicators of connective tissue metabolism and basic microelements in order to determine the role of undifferentiated connective tissue dysplasia in the pathogenesis of functional cervical insufficiency during pregnancy.

\section{Materials and methods}

A prospective clinical examination of 101 pregnant women, "main group", in the gestation period between 22 and 32 weeks with a diagnosis of "Functional cervical insufficiency" was conducted during 2015-2017. "Control group" included 34 pregnant women with the physiological obstructive function of the cervix. All women were treated in the Department of Pathology of Pregnancy and Delivery, State Institution "Institute of Pediatrics, Obstetrics and Gynecology named after academic A. M. Lukyanova of NAMS" (Kyiv, Ukraine).

All pregnant women were examined in accordance with the quality standards of the antenatal care program. The clinical diagnostic criteria for CI included: the cervix opening $\geq 2 \mathrm{~cm}$ in the absence of uterine contractions and placental abruption, prolapse of the fetal bladder from the external orifice of the uterus. During a transvaginal ultrasound examination, the diagnosis was confirmed in the case of cervix shortening $\geq 25 \mathrm{~mm}$, the presence of the wedge-shaped transformation of the cervical canal by $\geq 40 \%$ of its length $[18,19]$. All pregnant women were offered to undergo a voluntary clinical interview in order to identify phenotypic manifestations of UCTD (myopia, varicose disease, vegetative-vascular dystonia, osteochondrosis, biliary dyskinesia, nephroptosis) [11].

In order to determine the role of UCTD in the genesis of functional CI, the concentration of collagen metabolism products and the most important microelements were determined. The study was conducted utilizing ELISA in the Laboratory of Biochemical and Clinical Analysis of State Institution "The Institute of Traumatology and Orthopedics" of NAMS (Kyiv, Ukraine). The concentration of synthesis marker Total $\mathrm{P}_{1} \mathrm{NP}$ (amino-terminal propeptide of type I procollagen), resorption marker $\beta$ - CrossLaps of CT (utilizing automated analyzer Cobas-411 (RocheDiagnostics, USA)), the contents of trace elements $\mathrm{Na}^{+}, \mathrm{K}^{+}, \mathrm{Mg}^{2+}, \mathrm{Ca}^{2+}$ and total $\mathrm{Ca}$ and $\mathrm{P}$ (utilizing automatic analyzer of electrolytes and a set of reagents for determining Easylyte (Medica, USA)) were determined in the serum of pregnant women.

Statistical comparisons were conducted using Student's t-test and Fisher's angular transformation. Quantitative data were expressed as the mean value \pm SEM. The calculations were performed using software STATISTICA for Windows and Microsoft Excel 10.0. If $p<0.05$ the difference was considered significant. The results were compared using multiple correlation data analysis and calculation of Pearson linear correlation coefficient (r) [20].

\section{Results of the research}

According to age, place of residence, social and family status pregnant women of the main and control groups were homogeneous, that allowed us to study differences caused by CI. It was determined that $77(76.2 \%)$ of pregnant women in the main group had diseases and conditions that are clinical signs of UCTD. The diseases of the cardiovascular system (54 pregnant women in the main group $-53.5 \%$, and 8 pregnant women in control group $-23.5 \%, \mathrm{p}<0.05$ ), ophthalmic pathology (26 pregnant women in the main group $-25.7 \%, 3$ pregnant women in control group $-8.8 \%$; $\mathrm{p}<0,05$ ), diseases of the gastrointestinal tract and hepatobiliary system (42 pregnant women in the main group $-41.6 \%, 7$ pregnant women in control group $-20.6 \%$; $<0,05$ ) were significantly more often detected. The diseases of urinary (9 pregnant women $-26.4 \%$ ) and cardiovascular systems (8 pregnant women - $23.5 \%$ ) and ENT-organs (ear, nose, and throat) (8 pregnant women $23.5 \%)$ prevailed in pregnant women of the control group. The primigravidas represented the 
majority within examined pregnant women $(54.5 \%$, of the main group, $55.9 \%$ of the control group) as well as by multigravidas who were going to give a birth for the first time (the main group $45.5 \%$, control group $44.1 \%$ ).

Transvaginal ultrasound examination revealed that length of the cervix in pregnant women of the main group had ranged between 8 and $32 \mathrm{~mm}$. The average length was $22.88 \pm 1.02 \mathrm{~mm}$ that was considered as a predictor of premature delivery. The average value of the cervix length in the pregnant women of the control group was $37.44 \pm 0.44 \mathrm{~mm}(\mathrm{p}<0.05)$ that corresponds to normal physiological parameters.

In order to estimate the condition of cervical fibrous connective tissue the concentration of Total $\mathrm{P}_{1} \mathrm{NP}$, a marker of the type I collagen synthesis was determined in the serum of pregnant women. The concentration of P1NP was significantly increased $(68.15 \pm 3.55 \mathrm{ng} / \mathrm{ml})$ in the serum of pregnant women of the main group in comparison with values for the pregnant women from the control one $(50.90 \pm 4.27 \mathrm{ng} / \mathrm{ml} ; \mathrm{p}<0.05)$ and the physiological norm. The pregnant women from the control group had markers of production and resorption of type I collagen synthesis in balance that ensures the maintenance of proper physiological function of elastic fibers and cervix. At the same time, the average value of CT resorption marker $\beta$-CrossLaps, a product of collagen degradation in pregnant women of both groups, was within the physiological norm $(0.390 \pm 0.02 \mathrm{ng} / \mathrm{ml}$ and $0.300 \pm 0.02 \mathrm{ng} / \mathrm{ml}$, respectively).

Considering dependence of the condition of connective and smooth muscle tissues on the micro-nutritional status, the content of trace elements was studied in blood serum of pregnant women of both groups. The results show increased total calcium concentration in pregnant women of the main group $(2.60 \pm 0.03 \mathrm{mmol} / \mathrm{l})$ compared with the physiological norm by $4.8 \%$ and with the same indicator of the pregnant women of the control group $(2.21 \pm 0.09 \mathrm{mmol} / \mathrm{l} ; \mathrm{p}<0.05)$ by $17.6 \%$. A similar trend was revealed for the indicators of ionized calcium $(1.39 \pm 0.02 \mathrm{mmol} / \mathrm{l})$, which exceeded average physiological norm and values in pregnant women of the control group $(1.11 \pm 0.03 \mathrm{mmol} / \mathrm{l} ; \mathrm{p}<0.05)$ by $5.3 \%$ and $25.2 \%$, respectively. The concentration of blood serum phosphorus in pregnant women of the main group $(1.50 \pm 0.02 \mathrm{mmol} / \mathrm{l})$ was significantly higher than in the control group $(1.13 \pm 0.06 \mathrm{mmol} / \mathrm{l} ; \mathrm{p}<0.05)$ by $32.7 \%$ and by $3.4 \%$ exceeded the physiological norm. The average concentrations of magnesium ions, which are involved in the metalloproteinases functions and regulate degradation or proteolysis of collagen fibers, was lower in blood serum of pregnant women of the main group $(0.64 \pm 0.01 \mathrm{mmol} / \mathrm{l})$ comparing with the control group values $(0.86 \pm 0.03 \mathrm{mmol} / \mathrm{l} ; \mathrm{p}<0.05)$ by $25.6 \%$ and by $3.0 \%$ lower than physiological norm. The results show the decreased concentration of potassium ions in the blood serum of pregnant women of the main group $(3.29 \pm 0.09 \mathrm{mmol} / \mathrm{l})$ in an average by $6 \%$ comparing to the physiological norm and by $20.5 \%$ comparing to values in pregnant women of the control group $(4.14 \pm 0.21 \mathrm{mmol} / \mathrm{l} ; \mathrm{p}<0.05)$. A similar trend was observed for ionized sodium concentration. The average value in blood serum of pregnant women of the main group $(127.57 \pm 1.72 \mathrm{mmol} / \mathrm{l})$ was lower than the physiological norm by $5.5 \%$ and by $9.7 \%$ lower than the values in the control group $(141.29 \pm 5.81 \mathrm{mmol} / \mathrm{l} ; \mathrm{p}<0.05)$.

\section{Discussion of the results}

The accumulation of type I collagen in the cervix promotes premature tissue softening, opening of the internal orifice and cervical canal during pregnancy leading to the manifestation of premature delivery. The predominance of the type I collagen synthesis over the resorption is one of the leading factors in the pathogenesis of asymptomatic progressive softening, shortening and opening of the cervix. Our study has shown increase in pregnant women blood serum of marker of connective tissue synthesis that coincides with the results of Oxlund et al. [21] and Bohîlțea et al. [22]. The revealed observations confirmed by correlation analysis. The pregnant women of the main group characterized by a strong inverse correlation $(\mathrm{r}=-0.7362)$ between the length of cervix and concentration of connective tissue synthesis marker Total $P_{1}$ NP (Fig. 1).

The concentration of calcium ions determines the activity of elastin fibers and takes part in the activation of elastase centers $[16,17]$. Therefore, the change in concentration of total and ionized calcium worsens the properties of both connective tissue and organs. Thus, the ratio between calcium and phosphorus in the blood serum of pregnant women in the main group was 1.7:1. These 
data suggest about the increase in the amount of muscle tissue in the cervix that occurs during pathological replacement of CT with smooth muscle tissue.

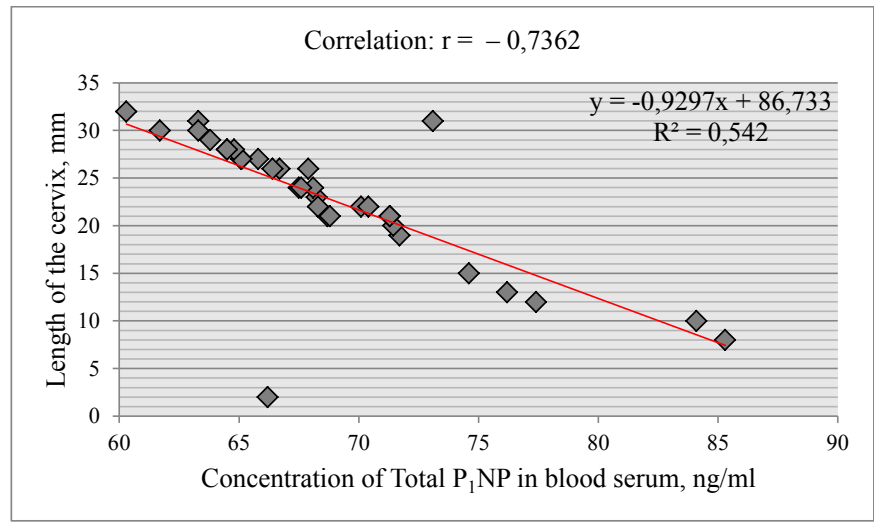

Fig. 1. Inverse correlation $(r=-0.7362)$ between concentration of Total $P_{1} N P$ and cervical length of pregnant women in the main group

The statistical analysis (Fig. 2) revealed strong inverse correlation $(\mathrm{r}=-0.7505)$ between $\mathrm{Mg}^{2+}$ concentration and marker of $\mathrm{CT}$ synthesis Total $\mathrm{P}_{1} \mathrm{NP}$ in blood serum of pregnant women of the main group. The results confirm the correlation between CT and magnesium concentration and indicate the persistent insufficiency of the cervical opening in the examined pregnant women.

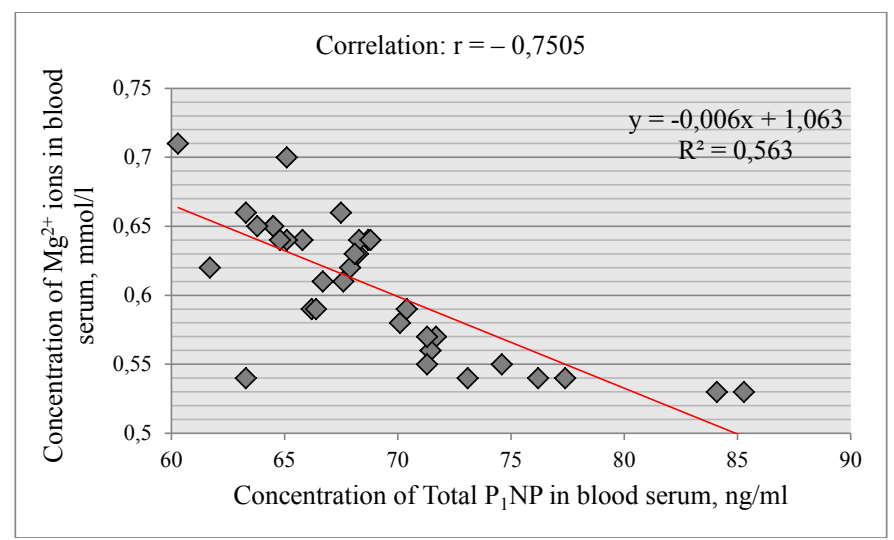

Fig 2. Inverse correlation $(r=-0.7505)$ between concentration of Total $\mathrm{P}_{1} \mathrm{NP}$ and $\mathrm{Mg}^{2+}$ ions in blood serum of pregnant women in the main group

The magnesium status, which was registered in pregnant women of the main group, might be one of the reasons for membrane transport perturbation and disbalance of $\mathrm{Na}^{+} / \mathrm{K}^{+}$.

Therefore, a thorough study of the hormonal status and the correlation analysis between markers of synthesis and resorption of connective tissue and essential hormones during pregnancy in pregnant women is advisable. The obtained results would enable prediction at preclinical stage of pathological changes in structure of cervix and enable determination of the appropriate pathogenetically based therapy for pregnant women.

\section{Conclusions}

1. Primigravidas with clinical manifestations of undifferentiated connective tissue dysplasia are a high-risk group for the development of cervical insufficiency during pregnancy and require preconceptional pregravidal preparation.

2. The imbalance of concentration of markers of connective tissue synthesis and resorption, basic microelements and their rations is a sign of high probability of the undifferentiated connective tissue dysplasia and premature cervical maturation in case of cervical insufficiency. 
3. It is recommended to include collagen and matrix protective treatments into the preconception therapy program of patients with phenotypic symptoms of the undifferentiated connective tissue dysplasia.

\section{References}

[1] Cavalcante, M. B., Costa, F. da S., Araujo Junior, E., Barini, R. (2014). Risk factors associated with a new pregnancy loss and perinatal outcomes in cases of recurrent miscarriage treated with lymphocyte immunotherapy. The Journal of Maternal-Fetal \& Neonatal Medicine, 28 (9), 1082-1086. doi: http://doi.org/ 10.3109/14767058.2014.943175

[2] Alzahrani, D. A. (2016). Progestrone uses in obstetrics and gynecology, MedCrave Online Journal of Women's Health, 2 (5), 127-128. doi: http://doi.org/10.15406/mojwh.2016.02.00046

[3] Pasek, R. C., Dunn, J. C., Elsakr, J. M., Aramandla, M., Matta, A. R., Gannon, M. (2017). Vascular-derived connective tissue growth factor (Ctgf) is critical for pregnancy-induced $\beta$ cell hyperplasia in adult mice. Islets, 9 (6), 150-158. doi: http://doi.org/10.1080/19382014.2017.1356963

[4] Aleman, A., Althabe, F., Belizan, J., Bergel, E. (2002). Bed rest during pregnancy for preventing miscarriage. Cochrane Database Systematic Reviews, 2. doi: http://doi.org/10.1002/14651858.cd003576

[5] Balogun, O. O., da Silva Lopes, K., Ota, E., Takemoto, Y., Rumbold, A., Takegata, M., Mori, R. (2016). Vitamin supplementation for preventing miscarriage. Cochrane Database of Systematic Reviews, 5. doi: http://doi.org/10.1002/14651858.cd004073.pub4

[6] Lee, H. J., Park, T. C., Norwitz, E. R. (2009). Management of pregnancies with cervical shortening: a very short cervix is a very big problem. Reviews in Obstetrics and Gynecology, 2 (2), 107-115.

[7] De-Regil, L. M. (2012). Vitamin D supplementation for women during pregnancy. Cochrane Database of Systematic Reviews, 2. doi: http://doi.org/10.1002/14651858.cd008873.pub2

[8] Norman, J. E., Marlow, N., Messow, C.-M., Shennan, A., Bennett, P. R., Thornton, S. et. al. (2016). Vaginal progesterone prophylaxis for preterm birth (the OPPTIMUM study): a multicentre, randomised, double-blind trial. The Lancet, 387 (10033), 2106-2116. doi: http://doi.org/10.1016/s0140-6736(16)00350-0

[9] Marder, W., Littlejohn, E. A., Somers, E. C. (2016). Pregnancy and autoimmune connective tissue diseases. Best Practice \& Research Clinical Rheumatology, 30 (1), 63-80. doi: http://doi.org/10.1016/ j.berh.2016.05.002

[10] Saar, P., Hermann, W., Müller-Ladner U. (2006). Connective tissue diseases and pregnancy. Rheumatology (Oxford), 45 (3), 30-32.

[11] Vengetesh, P. M., Hebbar, S., Rai, L. (2015). Autoimmune diseases in pregnancy: maternal and fetal outcomes. International Journal of Reproduction, Contraception, Obstetrics and Gynecology, 4 (1), 9-14. doi: http://doi.org/10.5455/2320-1770.ijrcog20150202

[12] Dodd, J. M., Crowther, C. A. (2009). The role of progesterone in prevention of preterm birth. International Journal of Women's Health, 1, 73-84.

[13] Bloomfield, S. A., Martinez, D. A., Boudreaux, R. D., Mantri, A. V. (2016). Microgravity stress: bone and connective tissue. Comprehensive Physiology, 6 (2), 645-686. doi: http://doi.org/10.1002/ cphy.c130027

[14] Balc, A. K., Koksal, O., Kose, A., Armagan, E. (2013). General characteristics of patients with electrolyte imbalance admitted to emergency department. World Journal of Emergency Medicine, 4 (2), 113116. doi: http://doi.org/10.5847/wjem.j.issn.1920-8642.2013.02.005

[15] LaRusso, J., Li, Q., ${ }^{\text {Jiang, }}$ Q., Uitto, J. (2009). Elevated dietary magnesium prevents connective tissue mineralization in a mouse model of pseudoxanthoma elasticum (Abcc6(-/-). Journal Investigative Dermatology, 129 (6), 1388-1394. doi: http://doi.org/10.1038/jid.2008.391

[16] Koshel, M. V., Chebotarev, V. V. (2014). Acne treatment in patients with connective tissue dysplasia. Medical news of North Caucasus, 9 (2), 170-172. doi: http://doi.org/10.14300/mnnc.2014.09048

[17] Fujita, Y., Goto, S., Ichikawa, M., Hamaguchi, A., Maki, K. (2016). Effect of dietary calcium deficiency and altered diet hardness on the jawbone growth: A micro-CT and bone histomorphometric study in rats. Archives of Oral Biology, 72, 200-210. doi: http://doi.org/10.1016/j.archoralbio.2016.08.036

[18] Clinical guideline for obstetric care (2008). Ministry of public health of Ukraine from 03.11.2008. No. 624. «Miscarriage». 
[19] Quinn, J.-A., Munoz, F. M., Gonik, B., Frau, L. (2016). Preterm birth: Case definition \& guidelines for data collection, analysis, and presentation of immunisation safety data. Vaccine, 34 (49), 6047-6056. doi: http://doi.org/10.1016/j.vaccine.2016.03.045

[20] Dakhale, G. N., Hiware, S. K., Shinde, A. T. (2012). Basic biostatistics for post-graduate students. Indian Journal of Pharmacology, 44 (4), 435-442. doi: http://doi.org/10.4103/0253-7613.99297

[21] Oxlund, B. S., Ortoft, G., Brüel, A., Danielsen, C. C., Oxlund, H., Uldbjerg, N. (2010). Cervical collagen and biomechanical strength in non-pregnant women with a history of cervical insufficiency. Reproductive Biology and Endocrinology, 8, 92. doi: http://doi.org/10.1186/1477-7827-8-92

[22] Bohiltea, R. E., Munteanu, O., Turcan, N., Baros, A., Bodean, O., Voicu, D., Cirstoiu, M. M. (2016). A debate about ultrasound and anatomic aspects of the cervix in spontaneous preterm birth. Journal of Medicine and Life, 9 (4), 342-347.

\title{
PROGNOSTIC VALUE OF COGNITIVE TESTS AND THEIR COMBINATION IN PATIENTS WITH CHRONIC HEART FAILURE AND REDUCED LEFT VENTRICULAR EJECTION FRACTION
}

\author{
Leonid Voronkov \\ Department of heart failure \\ National Scientific Center "M. D. Strazhesko Institute of Cardiology" \\ 5 Narodnoho opolchennya str., Kyiv, Ukraine, 02000 \\ lgvoronkov@gmail.com \\ Anastasiia Solonovych \\ Department of heart failure \\ National Scientific Center "M. D. Strazhesko Institute of Cardiology" \\ 5 Narodnoho opolchennya str., Kyiv, Ukraine, 02000 \\ stasyasol85@gmail.com \\ Alina Liashenko \\ Department of heart failure \\ National Scientific Center "M. D. Strazhesko Institute of Cardiology" \\ 5 Narodnoho opolchennya str., Kyiv, Ukraine, 02000 \\ lyashenko2007@ukr.net \\ Ivanna Revenko \\ National Scientific Center "M. D. Strazhesko Institute of Cardiology” \\ 5 Narodnoho opolchennya str., Kyiv, Ukraine, 02000 \\ ivarev@ukr.net
}

\footnotetext{
Abstract

Impaired cognitive function (CF) is common among patients with $\mathrm{CHF}$ and is an additional factor impairing the quality of life, adherence to treatment, and hence the clinical prognosis in this category of patients.

The aim of this work was to study the prognostic significance of individual cognitive tests, as well as their combination in patients with CHF with a reduced left ventricular ejection fraction (LV EF).

Materials and methods. The study was conducted in the Department of Heart Failure of National Scientific Center "M.D. Strazhesko Institute of Cardiology" National Academy of Medical Sciences of Ukraine, in the period from 01/01/2016 to 04/27/2018. A total of 124 patients with CHF between the ages of 18 and 75 years, II-IV functional classes by NYHA were examined. The cognitive function was assessed using the Schulte test, Mini-Mental State Examination scale (MMSE); HADS scale. Cognitive dysfunction (CD) was considered as MMSE $\leq 26$ points. To construct the survival curves and the onset of the combined critical event
} 